\title{
THE RELEVANCE OF SHORT SALES TO THE MALTESE STOCK MARKET
}

\section{Paul V. Azzopardi ${ }^{\S}$ and Silvio J. Camilleri"}

\begin{abstract}
The paper discusses the possible effects of short sales on the operation of a very small stock market such as the Maltese one. After studying the basic mechanics of short selling procedures, the paper reviews the salient literature with particular reference to how short sales may enhance informational efficiency and their relationship with liquidity. The paper proceeds by examining these relationships in the context of the Maltese securities market. The study reveals that short sales may be desirable on the Maltese stock market for enhancing price efficiency and liquidity, yet a more formal framework for conducting such transactions is required. In addition, short positions may be particularly risky in the context of the Maltese stock market, due to low liquidity levels.
\end{abstract}

\section{Introduction}

A short sale is defined as the selling of an asset which is not actually owned by the trader at the time the transaction occurs. One may mention a variety of businesses whereby an asset is sold and acquired later, for example importation and housing contracts. The objective of this analysis is to apply the principal theories related to short selling of financial assets to the Maltese securities market.

The paper is organised as follows. The next section describes how short sales are conducted, the restrictions which could apply to these transactions and the rationale behind them. This is mainly intended for readers who are not familiar with the subject. Section 3 presents a briefliterature review while the subsequent section discusses the main bodies of theory

$\S$ Paul V. Azzopardi is a stockbroker and founder member of the Malta Stock Exchange. I Silvio J. Camilleri lectures at the Banking and Finance Department of the Univeristy of Malta. 
in the context of the Maltese securities market. Section 5 concludes the analysis.

\section{Short Selling Procedures}

A short sale occurs when a trader borrows shares (or some other asset) which he then sells to a third party. When the short seller is required to refund the shares back to the lender, he purchases them on the market, hopefully at a price which is less than the one prevailing in the former transaction. In this way, short sales yield a profit when share prices fall.

The nature of short sale transactions requires certain procedures or formalities which are designed to deal with the credit risk on part of the short seller and to avoid destabilising the market. For example, securities lending usually requires the short seller to provide cash collateral which is equal to the market value of the securities, and he may also be asked to increase his collateral if the prices of the relevant securities rise.

If the shorted stocks pay a dividend, the short seller is required to compensate the lender of the securities (whose holdings were sold short) for the "lost" dividends. The short seller's cost may be redeemed since share prices usually decline on dividend date and therefore a lower cash collateral requirement may compensate for this dividend obligation.

In the US, margin customers of brokers sign an agreement which empowers the broker to lend their securities to third parties. When the broker actually lends the securities to the short seller, the owner of the securities will not note any material changes - she can still sell her shares and obtain dividends. At times, cash account customers authorise brokers to lend their stocks. The cash collateral which is provided by the short seller is usually invested in the money markets and earns a return in the process.

Perhaps the most significant risk associated with short selling is that the short seller, having to close his position by buying shares on the market, may have to pay a premium in order to find a willing seller. At times, market participants "corner" the supply of a security i.e. the holdings of the particular share issue become concentrated in the hands of a few 
large shareholders. In such cases, short sellers find it difficult to borrow or to buy the stock. The short sellers are thus "cornered" and they end up at the mercy of a few shareholders who may demand a higher price to give up their holdings. The deliberate cornering of a market is usually considered as an attempt at market manipulation. For example, corners were used as part of wider programmes of market manipulation on the New York Stock Exchange in the early twentieth century.

Another risk which should be considered by the short seller is related to the voting rights of the shares which are sold short. At times, both the owner of the securities who lent her holdings to the short seller, and the third party buyer of the securities, may want to exercise their voting rights. Usually obtaining a proxy from other shareholders who are not interested in voting is not a problem, but in strongly contested elections, the broker may have to ask the short seller to close out his position by buying shares back on the market. The risk from the point of view of the short seller is that he may be requested to unwind his position prematurely, perhaps at an unfavourable price, unless the stockbroker's agreement specifies how to go about such a situation.

Finally, the short seller has to consider the monetary costs of depositing cash collateral, in terms of forgone interest.

Regulations may restrict short sales in specific circumstances. For example, stock market regulators in some countries try to prohibit those short sales which may depress market prices. In the US, this requirement is implemented through the Zero-Plus Tick Rule. This specifies that a short sale can only take place if the last transaction price was higher than the preceding one. Alternatively, if the price was unchanged during the last transaction, a short sale may take place if the preceding price change was an upward one (Teweles and Bradley, 1998). In this way, short sellers cannot initiate a downward trend in the price of the relevant stock or accelerate a declining market.

Other restrictions result from the fact that not all stocks are actually available for lending (Hansell, 1992). Finally, certain classes of investors, for example pension funds, might have external or internal restrictions on short positions. 
Short sales have earned a somewhat negative reputation because they may be viewed as strategies that aim at profiting from the distress of the markets at large. In fact short sales were partly blamed for the October 1987 crash in the US and the 1991 stock market crash in Japan (Wada, 1992). Some investors believe that short sales cause a downward price movement because they are interpreted as an indication that the particular stock being short sold is overpriced. On the other hand, others argue that, given that short sellers will eventually have to reverse their positions by buying the stock, their future actions will cause stock prices to increase (Woolridge and Dickinson, 1994). Usually an investor buys first and sells later; the share seller sells first and buys ("covers") later.

It is relevant to point out that short sales are important for the proper functioning of financial markets - as seen in the next section they increase the informational efficiency in the pricing process. In addition, short sales are often included as part of the investment strategies of professional arbitrage traders and hedge funds. One such example occurs when a takeover bid is announced, where arbitragers usually go long on the shares of the target company and short sell the shares of the bidding company.

Short sales are also an important tool used by market makers and stock exchange specialists. When the latter experience an excessive demand for a particular security, they can quickly exhaust their inventory of shares. Short selling enables the specialist to smooth price differences and maintain an orderly market. In this way, the presence of short sales may also be a sign of a bullish market, rather than a bearish one. Similar procedures occur when short sales are used to stabilise the prices of initial public offerings of shares.

\section{Brief Literature Review}

The theoretical foundations relating to short sales and stock market transactions are based on various assumptions. One of these is that traders make use of inside information in determining their investment strategies. This assumption may be subject to contention in those markets where insider trading is illegal. Another inherent assumption in most theoretical research is the presence of investors who continu- 
ously watch the market in order to trade as soon as they note that prices do not reflect all available information. The presence of large institutional investors implies that this is a reasonable assumption in the case of large stock markets. However it may not reflect the actual practice taking place in small stock markets such as the Maltese one. The assumption might also be unrealistic in the case of small stock issues in large markets. These assumptions have to be kept in mind when applying theoretical predictions to specific markets.

One fundamental research issue relates to how short selling facilitates the process through which stock prices impound information, particularly unfavourable news, as suggested by Diamond and Verrecchia (1987) and Figlewski and Webb (1993). This research reflected the notion that short sales serve as an indication of unfavourable information to the market at large. Bhattacharya and Gallagher (1991) argued that when information on short positions is not published instantaneously, markets cannot immediately adjust their expectations and strategies, slowing down this process.

Diamond and Verrecchia (1987) also tackled the issue of whether short sale constraints affect the speed of adjustment to good and bad news. The authors argued that if traders are prevented from selling short, then any periods of time during which no transactions occur may signify the presence of unfavourable information which cannot be traded upon through short sales. Traders watching the market are presumed to be able to compute the probability that the no-trade outcome is motivated by unfavourable information. In this way, the no-trade interval affects the pricing process and prices eventually adjust to full information, irrespective of the short-sale constraints. Therefore, it is argued that short sale constraints only serve to slow down the speed of adjustment (particularly to bad news) but do not inhibit prices from adjusting to their "true" levels.

Alternative markets, such as options and futures, may allow traders to go around short sale restrictions in the underlying market, by trading on a related instrument rather than on the stock itself. In this way, these alternative markets can prove to be an important venue for the incorporation of unfavourable information, as argued by Figlewski and Webb (1993) and Kyriacou and Mase (2000). In addition, options markets 
enable traders to bypass short sale requirements, such as the depositing of cash collateral, and they also enable traders to engage in strategies using higher leverage.

Research on short sales also investigated the differences between small and large stock issues. Elfakhani (2000) found that large stocks are sold short more often than small stocks, in absolute terms. However, small stocks attract more intensive short positions as compared to larger ones, i.e. a higher percentage of the outstanding shares are likely to be sold short in case of smaller issues. It is usually accepted that larger stocks are easier to short sell, given that the large amount of issued stocks implies that borrowing the stock may be easier and that the liquidity of the particular issue is likely to be higher. This explains why larger stocks attract more short sale activity in absolute terms.

The relatively larger short positions in small stocks are explained by two notions. The differential information hypothesis suggests that the popularity of small stocks as candidates for short sales may be due to the fact that the prices of less publicised small stocks are more sensitive to private information and therefore the return for trading on inside information tends to be higher (Barry and Brown, 1984). The liquidity hypothesis suggests that investors would want to shortsell these stocks to earn a higher expected return, in view of the higher inherent risk.

Theorists also investigated the effects of short sales on the liquidity of securities markets. Pollack (1986), as quoted in Alexander and Peterson (1999), argues that short selling is mainly undertaken by market professionals when exercising their role of providing liquidity to the market. In addition, short sales can boost liquidity if they help to stimulate healthy speculation and activity on the market.

\section{Short Sales in the context of the Maltese Securities Market}

Applying market microstructure theory to a given setting is not a straightforward task since each securities exchange tends to have its own particular characteristics in terms of size, trading systems and investor profile. In addition, other differences may emanate from differing objectives on part of regulators and people managing the particular 
exchange - the market "designers". Possible objectives which may be pursued by a market designer may include achieving a higher degree of pricing efficiency, reducing price volatility, enhancing liquidity or reducing transaction costs. These goals may at times conflict with each other. For example, markets that adjust rapidly to information are likely to exhibit higher price volatility. Given this, it is logical to start this section by describing the characteristics of the Maltese securities market.

\section{The Maltese Securities Market}

Equity turnover and volume on the Malta Stock Exchange for the years 1998 to 2002 are shown in Figure 1.*

The Malta Stock Exchange Index is shown in Figure 2 while Figures 3 to

Figure 1

\section{Equities Turnover 1998-2002 (Lm Millions)}

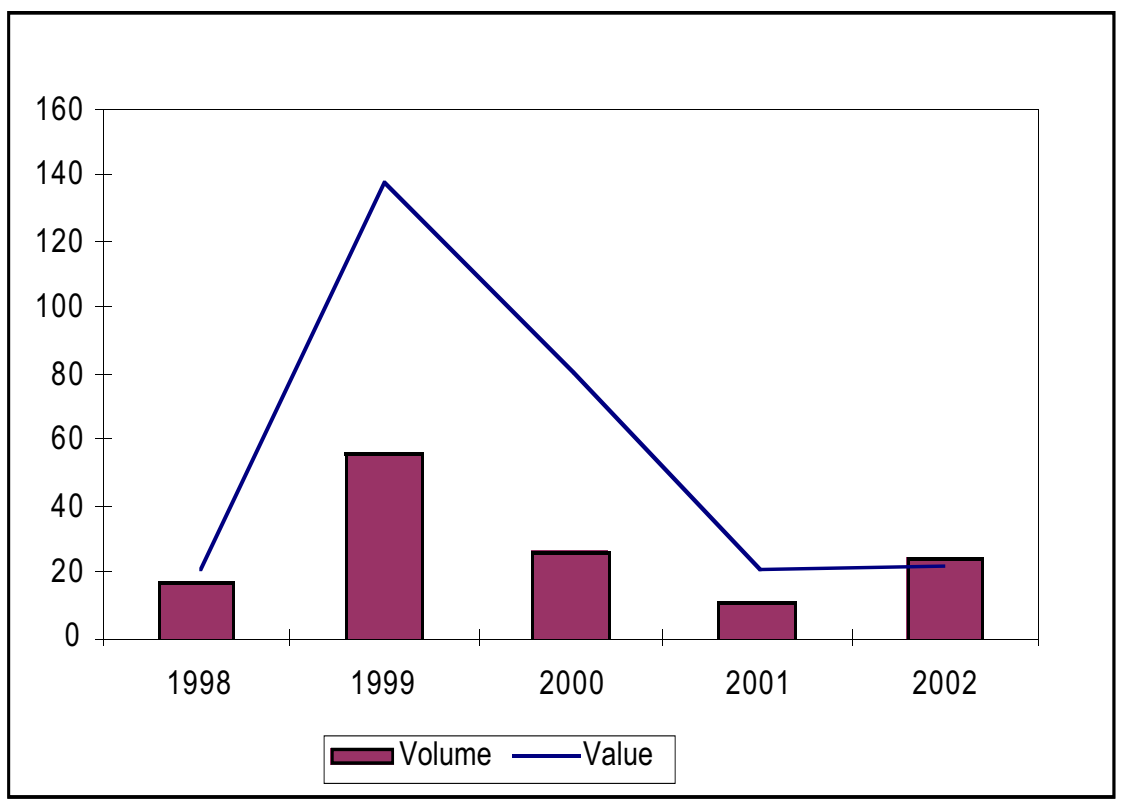

* The authors would like to thank Mr. Andrew Iles and Azzopardi Investment Management Limited for assistance with the graphs. 
Figure 2

Malta Stock Exchange Share Index

(27 Dec 95 - 28 Feb 03)

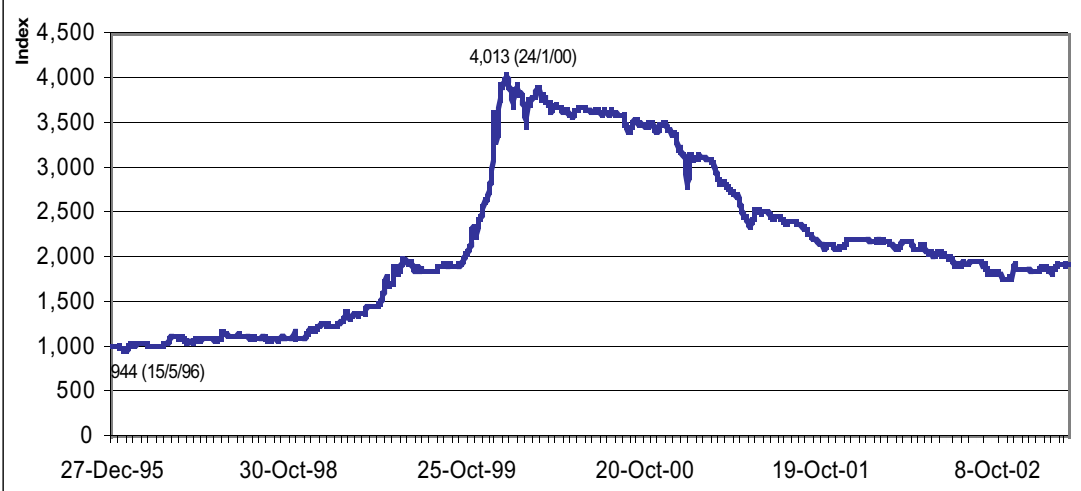

Figure 3

Bank of Valletta (7 Jan 98 - 28 Feb 03)

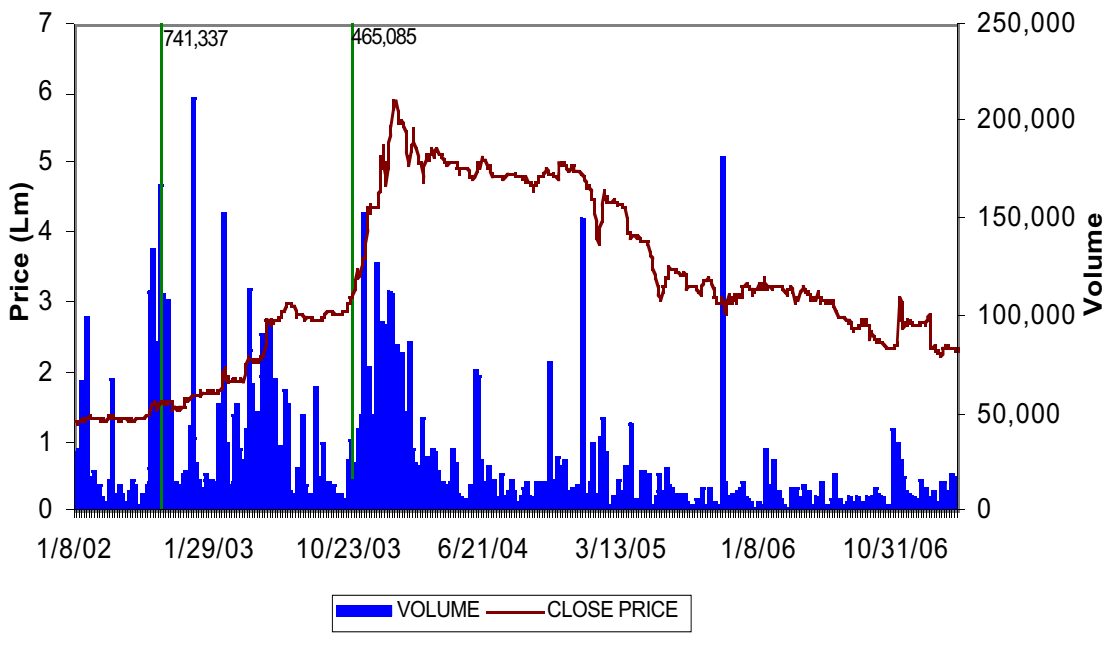


Figure 4

HSBC (7 Jan 98 - 28 Feb 03)

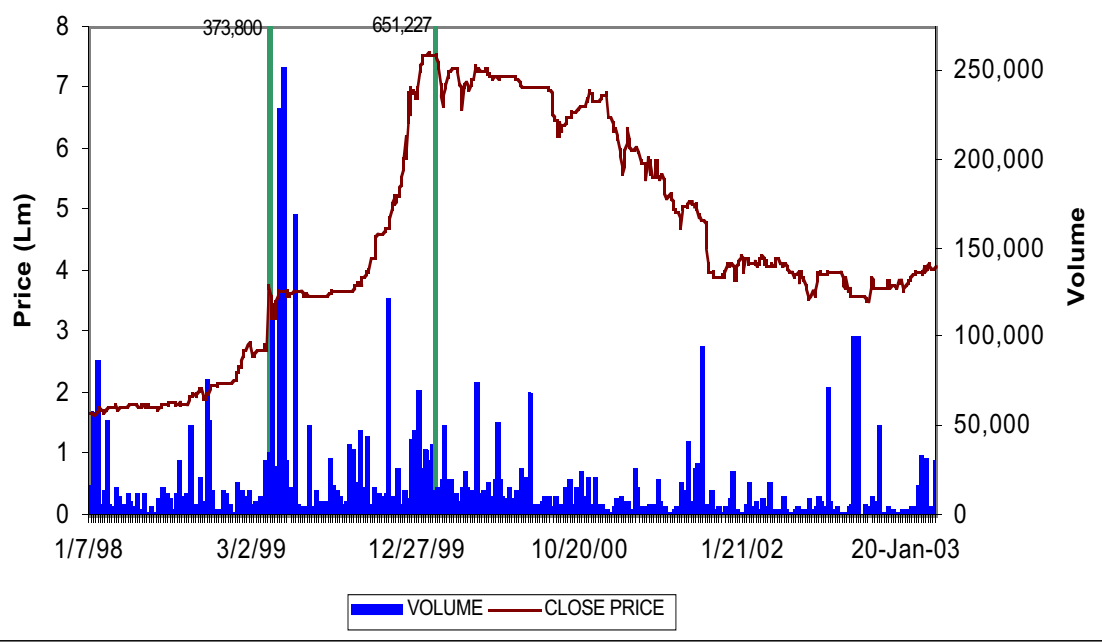

Figure 5

MaltaCom (23 Jun 98 - 28 Feb 03)

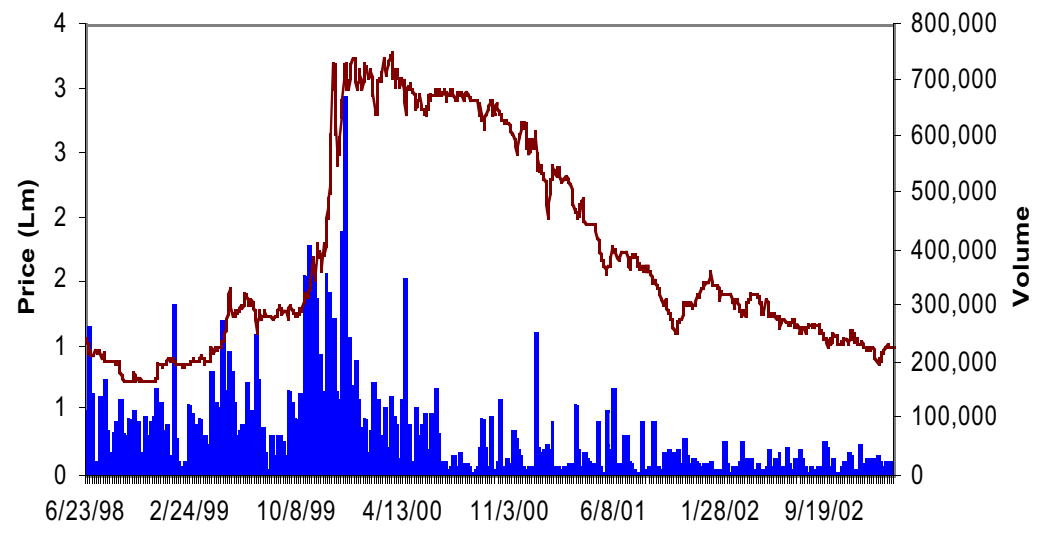

Date $(23 / 6 / 98$ - 28/2/03) 
5 are price and volume charts of Bank of Valletta plc, HSBC Bank Malta plc, and Maltacom plc. respectively.

In case of equities, late 1999 and early 2000 were the best periods in terms of turnover and price increases and this was also true for the individual major shares. As for government bonds, 2001 was the best year as a result of a shift in public demand from shares to bonds. Existing holders of government bonds, mostly the Central Bank in its role of market maker, ran out of them in 2002 and secondary market turnover was therefore low. Government bonds were issued, as usual, on the primary market but investors bought and retained them. Corporate bonds performed reasonably well in recent years as a result of the mentioned shift to bonds and increased issuance. As for equities in 2002, the average deal size was Lm 5,005 while for government bonds and corporate bonds the average deal size was higher at $\operatorname{Lm} 49,411$ and $\mathrm{Lm} 8,256$ respectively. Bond deals are generally larger in size than equity deals, in common with other markets. Volume is usually higher in case of government bonds, due to the presence of institutions that are willing to trade in higher volumes than the average investor. Listed shares are exempt from capital gains taxes and from stamp duty on transfer.

\section{Market Efficiency}

Liquidity and pricing efficiency generally vary with turnover and when this is adequate, the market in larger capitalisation equity issues and bonds is rather healthy and average size transactions occur at responsive prices. In the smaller capitalisation issues, one may encounter severe trading difficulties and prices may be sluggish.

The paucity of investors, analysts and stockbrokers who monitor the market on a continuous basis also limits price efficiency. During its first ten years of operation, the Malta Stock Exchange was serviced by around ten stockbroking firms whose representatives used to meet regularly on the floor. Once the market was developed and turnover levels increased, off-site electronic trading was introduced, new firms, including local banks, were granted licences and fixed commissions were abolished. Ironically, off-site trading via an electronic platform, whilst increasing price efficiency, led to the de-personalisation of the market since stockbrokers and/or their representative no longer meet daily to transact business. 
Market making is limited to government bonds and is conducted by the Central Bank. When the trading system was manual, the Central Bank as market maker had certain minor additional trading facilities which were done away with when electronic trading was introduced. Furthermore, since it is not considered best practice in larger markets for a central bank to act as market maker, or indeed to take up government bonds on issue, which might conflict with the monetary management role, the Central Bank has recently limited its role to providing a safety net for the bonds' bid prices. A market maker can assist price responsiveness but the market structure must be such that a number of market makers need be continually present and active to ensure competition.

An organised market brings together buyers and sellers in a controlled trading environment but does not, in itself, create demand or supply if a market is in fundamental disequilibrium. For example, at the time of writing, due to the huge money supply, the demand for government bonds is very much higher than supply and secondary trading is low since potential buyers are not willing to increase the price sufficiently and thus lower their entry yield to even lower levels.

\section{Short Sales in Maltese Securities Market}

The Malta Stock Exchange bye-laws, which regulate trading in detail, do not envisage short sales, although these procedures are not explicitly prohibited either. In the current setup, where share owners are registered at a Central Securities Depositary rather than held in street name, one might reasonably assume that short sales have to start with the securities lender's explicit consent. The transaction would be recorded subject to a private agreement in order to ensure that the short seller honours his obligations to the securities lender.

In the context of the Maltese securities markets, short sales may provide an important process for market participants to trade on overpriced securities thereby improving pricing efficiency. This necessity becomes more pronounced when one considers the virtual absence of any market making activity which assists in achieving higher information efficiency in the pricing process. Short sale activity, again, acquires a considerable degree of importance on the Maltese securities market in view of the absence of any derivatives activity on the securities traded in the 
country. As already agreed, derivatives markets present a venue where participants can trade on their beliefs of over-priced (or under-priced) securities.

In this way, short selling would be an important mechanism through which unfavourable information would be impounded in stock prices in a market where derivatives and market making activities are absent. This implies that, in such a setting, one should be concerned about short sale restrictions - in particular they should not be excessive. Onerous restrictions would impact on the pricing efficiency of the market, blocking unfavourable information from being incorporated into prices.

Market designers should also try to prevent the characteristics of a small market from acting as restrictions. For example, if short sales become a strategy which is used by a minority of investors - as does happen on larger markets - this may restrict short selling, in the sense that a significant portion of the participants might not even know of the existence of such strategies, or perhaps the way that they should be approached and when they should be undertaken.

Other subtle restrictions might also be the absence of an organised short sale function, and that such short positions are not published. Ideally the market should be organised and availing of instantaneous publication. As already explained, the publishing of short sale positions may also impact on the way in which participants adjust their expectations, and therefore the speed at which information is impounded in prices. Participants are not likely to adjust their expectations within a reasonable time period if short positions take long to get published - or if they remain as private agreements and not published at all! In addition, knowledge of current short positions is relevant for those participants who are considering going short, especially in the context of a low liquidity market, where securities might not be readily available for repurchase when the short positions are to be winded down. Instantaneous publishing of short positions would require identifying each sale - whether it is short or long - and therefore this marginal information may actually come at a higher transaction cost.

Short Sales and Volatility

In determining the actual restrictions on short selling procedures, 
market designers have to balance their objective of an efficient market with the objective of a less volatile one. The relationship between short sales and volatility may not be a straightforward one in the circumstances being discussed. One may argue that designers may reduce volatility on the markets if they apply somewhat tighter restrictions on short sales. As discussed in Section 3, prices would still eventually adjust to their efficient levels, only at a slower rate. This particular theoretical prediction may be even more evident in the Maltese context, given that unfavourable information is not usually impounded into prices through market making or derivatives activities. On the other hand, short sales may also be used to reduce volatility, such as when they are undertaken by market makers or specialists to stabilize demand, and this would call for fewer restrictions on short positions. However, the latter argument is not currently applicable to Maltese markets, given the absence of designated bodies whose functions specifically include stabilising the market.

\section{Small Stocks and Short Sales}

Market makers may at times have to satisfy some degree of demand through short sales. This may be very relevant to the Maltese securities markets, since investors tend to hold assets for long periods of time (in case of bonds up to maturity) and therefore the readily available securities might be less than optimal. In view of the fact that market making functions may eventually be introduced on the Maltese securities market, short selling would become a more important tool, due to such reasons. However, one has to point out that this process might turn out to be risky in these low liquidity circumstances, as outlined below.

Small stocks tend to be more popular with short sellers (at least in relative terms) and given this, it might be argued that the Maltese securities market may tend to be a very suitable location where to conduct such transactions. However, this may not necessarily be the case if we consider that one of the explanations why small stocks tend to be more popular for short selling relates to lower liquidity levels. In the context of the Maltese stock market, the latter factor may be deemed as too high a risk for market participants to engage in short positions.

This may be especially so in the case of the less "popular" securities, which at times do not trade for considerable periods, at times weeks. 
Thus, one might perhaps think of a "two-tier structure", whereby the more popular issues may be suitable candidates for short selling because of the possible returns for those who are willing to accept a somewhat high risk level. On the other hand, the liquidity risk on less traded stocks may be considered as too high and thus short sales are largely unadvisable.

The alternative explanation for the more intensive short positions in smaller stocks is centred on the fact that these stocks tend to be less publicised. Again, this may not always be applicable to the Maltese stock market, because notwithstanding the size of the issues, some of the securities tend to be widely publicised given that the issuers are of significant importance in the economy. Once more, a "two-tier" possibility is relevant whereby this time the less popular securities would be more suitable candidates for short selling. Therefore, the liquidity and the differential information hypothesis point at different classes of securities that may perhaps be suitable candidates for selling short. Thus, when applying these concepts to the Maltese securities market, the inherent small size does not indicate that it is highly suitable as a location in which to conduct short sales. Indeed, these theoretical studies were conducted in larger markets.

One main concern with short selling activities in the context of the Maltese securities markets would be that the short transactions undertaken may easily turn out to account for a proportionately high level of activity in such a small setting. In addition, the small number of participants in the Maltese market may mean that a large proportion of them would be only willing to undertake trades on the same "side" of the market, in the sense that situations might arise whereby a majority of orders would be buy orders or sell orders, thereby translating in higher volatility. However, given that theoretical arguments exist both for "bullish" and "bearish" effects emanating from short selling activity, concerns that short sales may depress the Maltese securities market might not be justified.

\section{Liquidity Risks}

The modest liquidity levels witnessed on the Maltese securities markets imply that one important objective on the part of a market designer vis- 
à-vis such a market would be to increase liquidity. Short sales may encourage a higher level of market activity in terms of making it easier to reap potential profits as any mispricings are ironed out. Thus they may contribute towards increasing liquidity levels.

However, short sales may be particularly risky to conduct in the Maltese stock market due to the low levels of liquidity. Indeed, the short sellers may have to close their positions at unfavourable prices due to the difficulty in finding a prospective seller of securities. As outlined above, the "cornering" of short sellers may also be part of a wider market manipulation activity. One should note that the potential for such collusion in the Maltese context may be quite significant given that the size of outstanding issues is small as compared to that of other markets, and therefore it is easier for holdings to become concentrated within a few key players. In addition, buying securities from minor participants may turn out to be difficult given that such investors often tend to hold their assets for a long period or till maturity, which partly explains the low numbers of transactions which take place on the Malta Stock Exchange.

The above suggests that there might be a vicious circle present in the Maltese securities markets, in the sense that raising liquidity may require the presence of short selling activity however the latter also requires a higher level of liquidity. If this is the case, one might argue that market designers face a challenging task. One should also note that while short sales may increase liquidity in larger markets, they might not be so effective in boosting liquidity of markets such as the Maltese one. This is due to the fact that the short sales might be largely discouraged by the inherent risk of having to close out the short position at unfavourable prices when these transactions are conducted in a low liquidity setting.

\section{Overview}

It would seem, therefore, that short sales may be desirable on the Maltese markets for pricing efficiency reasons, and in this way short sales should not be discouraged in principle. Despite this, short sales should be conducted whilst taking account of the Maltese market limitations, particularly the small size of the market with its inherent low liquidity. It is therefore important that short sellers are fully aware of the high 
liquidity risks which may be involved in such strategies. In addition, the parties must clearly agree beforehand how the short seller would be able to compensate the lender of the securities in the event that such assets are not available on the markets. In particular, the short seller might become involved in potentially unlimited liability if the securities lender insists that cash is not an acceptable alternative for compensation in case securities are not available on the market.

One might also ask whether it is optimal to have short sales taking place unofficially through private agreements - as must be done if any investors are willing to undertake such transactions under the current framework. Theory indicates that it is more desirable to have these transactions reported for price efficiency reasons. In attempting to create a systematic framework for short sale activities, one should avoid over-regulation since in practice this could amount to a prohibition. A second potential pitfall would be to simply replicate the framework of another exchange for ease of convenience-some procedures might make sense in one particular market, but might be totally unsuccessful in another setting.

Practitioners might welcome official guidelines or model agreements as to how one should ideally go about short sale procedures in order to ensure fairness to the securities lender, the short seller, and above all to control systematic risk.

\section{Conclusion}

This analysis started with a descriptive account of short sale activities and proceeded to give a brief survey of the relevant literature. The surveyed theories were then applied to the context of the Maltese securities market. It was seen that while short sales have desirable properties, especially with respect to pricing efficiency, formal and informal restrictions may hinder this function. Short sale activity may be particularly risky in the context of the Maltese market, due to its low liquidity level. This may have adverse impacts, in the sense that the potential for short sales to increase liquidity might also be hampered, and therefore, short sales on their own may not be sufficient to enhance liquidity levels on this market. 
The study provides indications on the possible impacts and desirability of short sales on the Maltese securities markets. Nonetheless, a more complete analysis might also focus on short sales in the context of other objectives of market designers, such as overall transaction costs of the market as well as the current regulatory setup and enforcement practices of the securities market.

\section{References}

ALEXANDER, G. and PETERSON, M. (1999) "Short Selling on the New York Stock Exchange and the Effects of the Uptick Rule," Journal of Financial Intermediation, Vol.8: 90-116

BARRY, C. and BROWN, S. (1984) "Differential Information and the Small Firm Effect," Journal of Financial Economics, Vol.13: 283-294. BHATTACHARYA, A.K. and GALLAGHER, G.W. (1991) "Causality Tests of Short Sales on the New York Stock Exchange," Journal of Financial Research, Vol. 14: 277-286.

DIAMOND, D.W. and VERRECCHIA, R.E. (1987) "Constraints on ShortSelling and Asset Price Adjustments to Private Information," Journal of Financial Economics, Vol.18: 277-311.

ELFAKHANI, S. (2000) "Short Positions, Size Effect, and the Liquidity Hypothesis: Implications for Stock Performance," Applied Financial Economics, Vol.10: 105-116.

FIGLEWSKI, S., and WEBB, G.F. (1993) "Options, Short Sales and Market Completeness," Journal of Finance, Vol.48: 761-777.

HANSELL, S. (1992) “The Other Side of Zero," Institutional Investor, April: 58.

KYRIACOU, K. and MASE, B. (2000) "Rolling Settlement and Market Liquidity," Applied Economics, Vol.32: 1029-1036.

POLLACK, I. M. (1986) Short-Sale Regulation of Nasdaq Securities, The National Association of Securities Dealers Inc.

TEWELES, R. and BRADLEY, E. (1998) The Stock Market, John Wiley and Sons Inc.

WADA, S. (1992) "Stock Lending Plummets along with Prices," The Nikkei Weekly, 11 July:16.

WOOLRIDGE, J.R. and DICKINSON, A. (1994) "Short Selling and Common Stock Prices," Financial Analysts Journal, Vol.50: 30-38. 